\title{
From Personal Misfortune to Public Liability
}

\author{
The Ethics, Limits, and Politics of Public Health Saving Ourselves from Ourselves
}

\author{
Leigh E. Rich • Michael A. Ashby
}

Received: 1 January 2013 / Accepted: 27 January 2013 /Published online: 27 February 2013

(C) Springer Science+Business Media Dordrecht 2013

The tension between a notion of the "common good" and individual liberty is one that political theory knows well. Indeed much of human political history is written around this central theme. In health matters, for example, we are now quite used to state regulation of products and practices that harm life or limb. The state, having a responsibility for the welfare of its citizens, has an accepted role - a duty, even - to mitigate exposure to harm, a sort of presumption in favor or even a casus belli in wars against public danger. The force majeure that justifies these regulations, including those associated with behavior and consumption, is the preservation of life itself and as such has found increasing support since the late 20th century in both the political process and the court of public opinion.

\footnotetext{
L. E. Rich $(\bowtie)$

Department of Health Sciences (Public Health),

Armstrong Atlantic State University,

11935 Abercorn Street, Solms 201,

Savannah, GA 31419, USA

e-mail: leigh.rich@armstrong.edu

M. A. Ashby

Palliative Care Service, Royal Hobart Hospital,

Southern Tasmania Health Organisation, and

School of Medicine, Faculty of Health Sciences,

University of Tasmania, Repatriation Centre,

1st Floor, Peacock Building, 90 Davey Street,

Hobart, TAS 7000, Australia

e-mail:michael.ashby@dhhs.tas.gov.au
}

Laws promoting smoking cessation and the use of seat belts or prohibiting drinking and driving and drug and alcohol abuse are all grounded in both common sense and scientific justifications that are hard to argue against. But as public health regulations have come into their own-turning from tobacco and alcohol to what we eat and how much-it is a reasonable necessity to ask where the limits of such state intervention and regulation might lie, lest excessive control infringe upon or even remove personal agency, risking both transgressions against autonomy and a Prohibition type of backlash that could undermine the public health impacts of well-intentioned policy. In other words, at what point should the state stop saving ourselves from ourselves? And what role does personal responsibility play-though we also must ask how much can be expected when structures in a capital-driven society purposefully seek to weaken self-efficacy (individuals' confidence in their ability to enact and carry out healthful decisions) or obstruct agency (individuals' actual capacity)? In societies where external loci of control are avidly sought when things go wrong, to what extent is it possible to experience personal misfortune without public liability? When is it "my responsibility" and when is it up to the government to restrict "my choices" as I cannot myself?

Part of the problem - and one that receives scant attention in consideration of public health - is that there is a side of human nature that is dark and 
destructive. Whilst there may be those who disagree with psychodynamic theory as a basis for understanding human behavior in 2013, Freudians are well used to the idea that human beings are driven by positive life forces (eros) and those of self-destruction (thanatos). Indeed what proportion of a day's work in an average hospital is the result of human self-destructive behavior in action: smoking, drug and alcohol use, accidents and injuries, suicide, and violence? Given that human beings do not behave in logical straight lines all of the time and that our personal lives are deeply complex, ambiguous, and emotional spaces, how should public health conduct itself and what limits should it set itself or have imposed upon it? For instance, smoking cessation programs long ago recognized the need to work at a very individual and interpersonal level (such as assisting people to identify their own "stage" of behavior change as well as triggers and coping mechanisms within their particular lives, with expert or lay helpers providing in-person, phone, or other support), and good obesity treatment programs do the same. In general, however, there is more stick than carrotperhaps because the burden of change in societies that make great profits peddling self-destructive pleasures cannot be borne by individuals alone. Thus, public health tends to work toward "engineering," at a minimum (see Alonzo 1993), or, at the extreme, regulation and prohibition wherever it can, thus promoting a "wowserish" (Australian-ism for "killjoy") image that can damage the good intentions of the mission while helping to shift emphasis away from individual obligation and engagement in leading a good life to state enforcement through bans and taxes.

A new generation of so-called "sin taxes" has been in the news recently. Like their predecessors that have focused on alcohol and tobacco, these are an attempt to reduce citizens' consumption of products linked with health risks and disease: sugar, fat, and/or salt. Most regions that have enacted some sort of foodbased tax have done so for reasons related to both the public's health and the health of medical infrastructures. The growing global problems of overweight and obesity, sedentary lifestyles, and poor nutrition are not only reducing the quality and duration of individuals' lives but also straining countries' health care resources. Taxes that increase the cost of certain food-related products are meant to sway people's choices at the supermarket or in a restaurant away from unhealthful items or, when still purchased, fund the health care systems being taxed - in a different way-by what has been called an obesity pandemic.

These taxes, however, have proven unpopular with industry and much of the public. Denmark, for example, announced late last year that it was abandoning its tax on products containing saturated fats, which was barely a year old, as well as its tax on chocolate and a proposed tax on sugar (Khazan 2012). The Danish government cited "increasing prices for consumers, increasing companies' administrative costs and putting Danish jobs at risk" as reasons for the decisions (Khazan 2012, ๆ2). Similarly, across the Atlantic, New York City's ban that limits the sizes of soda that restaurants can serve has been both criticized and the butt of jokes on news and late-night talk-show programs - even liberal-leaning ones (see, for example, The Daily Show With Jon Stewart) - and is currently being tested in the courts. The New York policy, however, likely will prevail, and other countries, including the United Kingdom, France, Finland, Hungary, Italy, and Romania, have contemplated or adopted food-related taxes comparable to Denmark's (European Public Health Alliance 2012).

Although it is perhaps too early to determine whether food taxes will flourish or fail, research has shown that taxes must be significant enough — which few currently are - to alter behavior (on the part of the consumer and the seller). Scholars and ethicists also have emphasized that taxation on its own is both unfair and unlikely to succeed in the larger goal of improving nutrition without subsidies on, and thus greater access to, healthier foods such as vegetables and fruits (Mytton, Clarke, and Rayner 2012). On the other hand, and no matter what commentators and comics claim about these latest taxes, public health advocates can point to the social and behavioral changes tobacco taxation and regulation have brought over the past half-century (though there is still much work to be done, especially globally). Increases in the financial costs of smoking have been tied to reductions in smoking rates, and many governments have limited or banned tobacco use in public places. Social norms related to tobacco also have transformed, and-with measures such as taxation and other forms of health promotion - many are hopeful the same fate will befall unhealthful foods.

While unpopular, taxes are perhaps a means of addressing the fundamental ethical concern between 
the common good and individual liberty (the so-called communitarianism versus liberalism issue; see Holland 2007) - a tension always felt in a discipline like public health. Unlike "traditional" bioethics, which grew out of the clinician-patient relationship and at least initially (and today in some circumstances) was more limited in scope (e.g., focused on an individual patient for a shorter period of time), public health and public health ethics must simultaneously take into consideration the interests of individuals, groups, and communities in both the short- and long-terms. (Of course, with a more holistic understanding of health care systems as well as biotechnologies that frequently benefit some at the expense of others, it has become easier to recognize the overlap between bioethics and public health ethics, which, in truth, are not so different.)

As public health practitioner Peter Geoffrey Sainsbury explains in this issue of the Journal of Bioethical Inquiry:

Public health is an applied, and essentially interventionist, discipline-it seeks to change individuals and change society to promote health. Traditionally, great emphasis has been placed on the public good: a utilitarian concern to maximise utility (health) in society as a whole, accepting that in the process some people may experience short- or even long-term harms. But practitioners also have had a strong liberal ethic to ensure that individual freedom is not unnecessarily constrained as well as a concern for equity, such that the harms and benefits arising from any action are shared fairly across society. Public health ethics is mainly applied ethics (Sainsbury 2013, ๆ9 under "Urban Planning as a Social and Ethical Activity").

Philosopher Stephen Holland, in his introductory text Public Health Ethics (2007), phrases Sainsbury's concerns in a slightly different way, urging public health professionals and policy-makers to be wary of and avoid naïve utilitarianism as a justifying mechanism for interventions.

From either perspective, it is clear that a strong understanding of ethical theory and application is essential for public health and its practitioners, particularly because much of the work done in public health is prescriptive.

Many public health initiatives, such as "sin taxes," employ a mix of health promotion and health protection (see Ratcliffe and Wallack 1986; Alonzo 1993; Mechanic 1999). Few public health advocates, ethicists, and policy-makers take issue with health promotion, which sometimes stops short at consciousness-raising and education (though there are some topics, particularly those that are stigmatized, for which certain legislators and advocacy groups find even education objectionable). Health protection, on the other hand, often calls into question social and corporate structures in the built environment that are risk-imposing and, thus, often calls for societal reform (Ratcliffe and Wallack 1986). This is a difficult and delicate dance: how to ensure greater health for all without sliding toward totalitarianism.

This may seem overstated - much like some of the comments of those "talking heads" with regard to "sin taxes" and the sizes of sodas. But no public health proposal, whether focused on important tasks and based on good intentions, should be immune from in-depth and ongoing dialogue. There is much at risk and potential for harms. (The descriptive side of public health - good surveillance and science-warrants attention, too.) Tragically, examples abound of immoral public health laws and programs propped up by discrimination and disreputable "science," all in the name of the "public good." The forced sterilization of hundreds of thousands throughout the world in the 20th century under the guise of an already discredited eugenic "science" and fostered by fears of disadvantaged socioeconomic classes costing taxpayers money is but one (see Lombardo 2008).

Decisions about what public health programs will be implemented and how cannot be one-sided, understudied, or opaque.

At the same time, particularly when it comes to the current crises of diabetes, stroke, and heart disease, health professionals and government leaders also cannot remain laissez faire. Deeming taxes on unhealthful consumptives or policies such as limiting vending machine sales in public schools as smacking of a "nanny state" may be hyperbolical. There are risks, too, of letting corporations run wild, beholden to shareholders and the accumulation of capital but immune from certain consequences and punishments for their own selfish behavior. With limited understandings and applications of corporate social responsibility - if it even can exist - are we to let corporations make their fortunes on the backs (and bodies) of the current and coming generations? 
At a time when economic liberalism has largely won the day in global politics, it is perhaps ironic that old-fashioned statism may be prevailing in health prevention. Taxes are, of course, only one small bite out of a very large elephant. Additional and ongoing efforts-at the structural as well as individual levelare needed to combat the non-communicable public health problems (physical, mental, social, spiritual, and environmental) associated with unhealthful foods (see, e.g., AFP relaxnews 2012; Deckers 2013), unhealthy body weight (see Vartanian and Smyth 2013; Upshur 2013), and inactivity.

On the other hand, if we critique the disadvantages of market-driven individualism in the modern world, it is somewhat contradictory to rely on otherwise passé tools of state intervention with only scant attention to the social consequences of the economic world order and its impact on individuals and societies: anxiety, pressure, insecurity, competition, and consumption. Every person who eats or drinks too much or smokes or takes illegal drugs does so as a result of a desire to calm inner emotions and unhappinesses. How is it that this individual psychodynamic perspective is so poorly developed and that family, education, and society "vandalized" by big business and straightjacketed by logical positive science are not subjected to a deeper and kinder scrutiny? Most of all, if liberalism finds an ally in existentialism, then Sartre's mauvaise foi would lead us to conclude that we must all take responsibility for ourselves, which is very much the message of modern selfmanagement approaches to chronic illness, such as with persistent pain. True health promotion needs to address our unhappy societies by reducing personal pressure, competition, and insecurity, starting in early childhood, so that people are able to implement healthy lifestyles, reduce risky behaviors, and thereby bankrupt corporations that can then no longer make huge profits by selling cigarettes, big bottles of sweet sodas, hamburgers full of fat and additives, alcoholic drinks aimed at teenagers, and sugar in everything. Medicalization is not the sole answer, where unhappiness, obesity, and addictions have to be turned into illnesses to make them socially acceptable and then treatable. Most of all some understanding of our own natures and darker sides would also be very valuable, a recognition that at best we are only ever logical part of the time. With notable religious exceptions most societies and peoples have some means of chemical escape from the pain and tedium that is part of all lives. Once we understand this, and can be kind to our contradictory natures, we can then surely work on the forces that we unconsciously direct upon ourselves in harmful and risky pursuits that result in thanatos, with much unhappiness in the way. But if we continue to mainly moralize and regulate, and, for instance, to lock up people whose personal pain and public disadvantage lead them to drug dependence, then our collective futures are bleak indeed.

The question, then, is how can and should public health motivate and enable individuals and communities toward healthful - not merely "lifestyles" butways of life? This issue of the Journal of Bioethical Inquiry offers a symposium edited by Stacy M. Carter and Lucie Rychetnik examining "Public Health Ethics and Non-Communicable Disease" and the challenges of attending to both health and liberty for all. Sure, some "sin taxes" may be a start, but these likely will not be sufficient to significantly change societal sources of self-destruction. What is needed is reformation of the individualistic, atomistic, and damaging view of humanity that merely pits "person" against "public" and fails to understand and appreciate life's complex interconnections and intersections. As legal scholar Wesley Newcomb Hohfeld underscored in his Fundamental Legal Conceptions as Applied in Judicial Reasoning (1919), in which he offered a set of four fundamental legal correlatives, liberties cannot exist in a vacuum. Guaranteeing the right of one must always place a duty on others.

\section{References}

AFP relaxnews. 2012. France proposes "Nutella tax" on palm oil: In addition to being a health risk, the industrial use of palm oil has led to widespread deforestation in Borneo, Sumatra and Indonesia, displacing and killing endangered populations of orangutans. New York Daily News, November 9. http://www.nydailynews.com/lifestyle/eats/france-proposes-nutella-tax-palm-oil-article1.1199417\#ixzz2JEsSOhMu.

Alonzo, A.A. 1993. Health behavior: Issues, contradictions and dilemmas. Social Science \& Medicine 37(8): 1019-1034.

Deckers, J. 2013. Obesity, public health, and the consumption of animal products: Ethical concerns and political solutions. Journal of Bioethical Inquiry 10(1). doi:10.1007/s11673012-9411-x. 
European Public Health Alliance. 2012. Food taxation in Europe: Evolution of the legislation. http://www.epha.org/ $\mathrm{a} / 4814$.

Hohfeld, W.N. 1919. Fundamental legal conceptions as applied in judicial reasoning. And other legal essays. Ed. W.W. Cook. New Haven: Yale University Press.

Holland, S. 2007. Public health ethics. Cambridge: Polity Press.

Khazan, O. 2012. What the world can learn from Denmark's failed fat tax. The Washington Post, November 11. http://www. washingtonpost.com/blogs/worldviews/wp/2012/11/11/ what-the-world-can-learn-from-denmarks-failed-fat-tax/.

Lombardo, P.A. 2008. Three generations, no imbeciles: Eugenics, the Supreme Court, and Buck v. Bell. Baltimore: The Johns Hopkins University Press.

Mechanic, D. 1999. Issues in promoting health. Social Science \& Medicine 48(6): 711-718.
Mytton, O.T., D. Clarke, and M. Rayner. 2012. Taxing unhealthy food and drinks to improve health. BMJ 344 : e2931. doi:10.1136/bmj.e2931.

Ratcliffe, J., and L. Wallack. 1986. Primary prevention in public health: An analysis of basic assumptions. International Quarterly of Community Health Education 6(3): 215-239.

Sainsbury, P.G. 2013. Ethical considerations involved in constructing the built environment to promote health. Journal of Bioethical Inquiry 10(1). doi:10.1007/s11673-012-9423-6.

Upshur, R. 2013. What does public health ethics tell (or not tell) us about intervening in non-communicable diseases? Journal of Bioethical Inquiry 10(1). doi:10.1007/s11673-012-9422-7.

Vartanian, L.R., and J.M. Smyth. 2013. Primum non nocere: Obesity stigma and public health. Journal of Bioethical Inquiry 10(1). doi:10.1007/s11673-012-9412-9. 